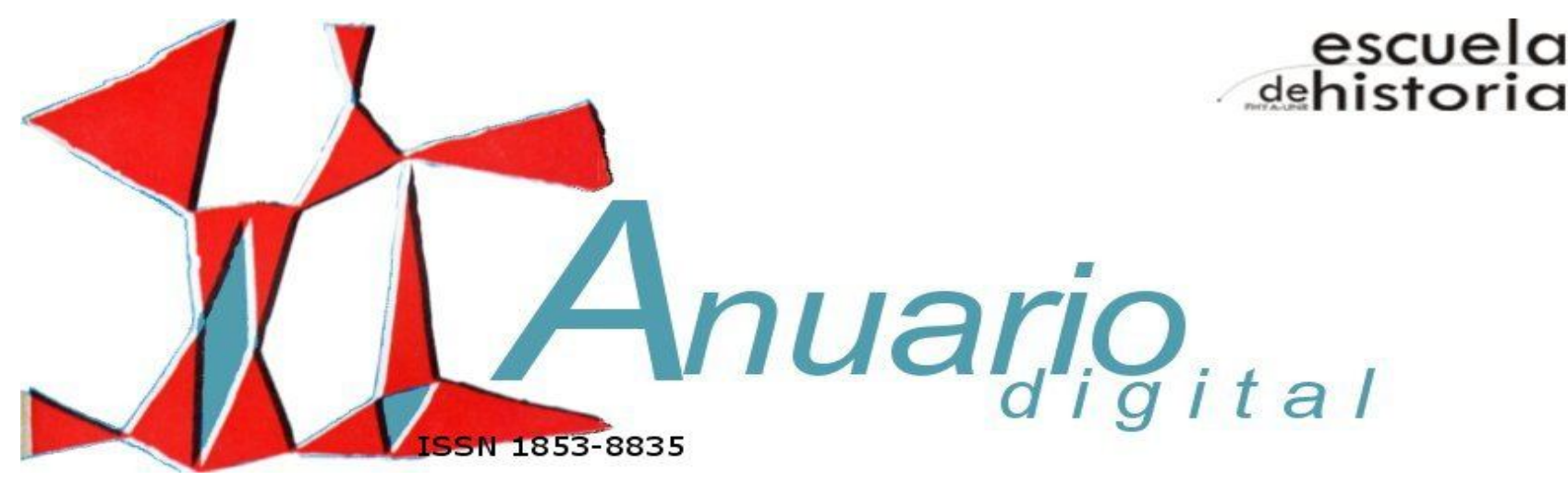

ÍNDICE

Dossier temático:

\title{
Debates y problemas de la historia europea antigua
}

Coordinación: Rodolfo Lamboglia

\section{PRESENTACIÓN}

Por Rodolfo Lamboglia (Universidad Nacional de Rosario)

$\checkmark \quad$ La Res Publica Romana: instituciones y participación popular

Francisco PINA POLO

(Universidad de Zaragoza)

$\checkmark$ El protagonismo de las mujeres en el Imperio romano. Del politeísmo tradicional al monoteísmo cristiano

Juana TORRES

(Universidad de Cantabria)

$\checkmark$ Debates actuales en torno a la economía del Principado, la crisis y las transformaciones en el período tardío Rodolfo LAMBOGLIA

(Universidad Nacional de Rosario)

$\checkmark$ Tendencias recientes en la investigación sobre las religiones antiguas

Francisco MARCO SIMÓN

(Universidad de Zaragoza)

Esta obra está sujeta a la Licencia Reconocimiento-NoComercial-CompartirIgual 4.0 Internacional de Creative Commons. 
$\checkmark \quad$ La Alejandría de Hipacia

Clelia MARTÍNEZ MAZA

(Universidad de Málaga)

\section{ARTÍCULOS}

$\checkmark$ Eugenio Gastiazoro: del MLN al PCR, de la Economía a la Historia (1939-1989)

Matías J. RUBIO

(Universidad Nacional de Luján)

$\checkmark$ Orlie Antoine de Tounens, ¿Un aventurero o un agente de Napoleón III?

Ricardo MÉNDEZ BAROZZI

(Universidad Nacional de Luján)

$\checkmark$ Exilio, debate y ruptura. Los balances de la Contraofensiva montonera de 1979 y la constitución de "Montoneros 17 de octubre"

Hernán Eduardo CONFINO

(Universidad Nacional de San Martín/Consejo Nacional de Investigaciones Científicas y Técnicas)

$\checkmark \quad$ La comisión investigadora $n^{\circ} 22$ : cuando la Revolución Libertadora llegó a YPF

Gabriel Alejandro CARRIZO

(Universidad Nacional de la Patagonia San Juan Bosco / Universidad Nacional de la Patagonia Austral/Consejo Nacional de Investigaciones Científicas y Técnicas)

\section{CONCURSO DE ESTUDIANTES:}

$\checkmark \quad$ El soviet de Humanidades. La crisis universitaria de 2001 en la Universidad Nacional de Rosario Agustina Kresic (Universidad Nacional de Rosario)

\section{RESEÑAS DE LIBROS}

$\checkmark$ TURCAN, Robert, Tiberio, Ciudad Autónoma de Buenos Aires: El Ateneo, 2018, [304 páginas].Por Juan Pablo Castagno (Universidad Nacional de Rosario)

$\checkmark$ HANSON, Víctor Davis (comp.), El arte de la guerra en el mundo antiguo. De las guerras persas a la caída de Roma: Barcelona, Crítica, 2012. [352 páginas]Por Juan José Noé (Universidad Nacional de Rosario)

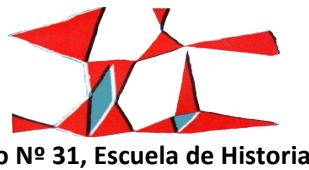

Anuario № 31, Escuela de Historia 